\title{
The Need of the Uniform Information Platform "Innovations of Russia" Formation
}

\author{
Elena Sibirskaya ${ }^{1}$, Olesya Stroeva ${ }^{2}$, Nadezhda Serebryakova $^{3}$ \& Elena Petruchina ${ }^{4}$ \\ ${ }^{1}$ Plekhanov Russian University of Economics, Moscow, Russia \\ ${ }^{2}$ Russian Presidential Academy of National Economy and Public Administration, Moscow, Russia \\ ${ }^{3}$ Voronezh State University of Engineering Technologies, Voronezh, Russia \\ ${ }^{4}$ Orel State University, Orel, Russia \\ Correspondence: Elena Sibirskaya, Plekhanov Russian University of Economics, 36, Stremyanny per., 117997, \\ Moscow, Russia. Tel: 79-10-269-0035. E-mail: e-sibirskaya@rambler.ru
}

\author{
Received: August 21, 2014 Accepted: September 15, 2014 Online Published: November 14, 2014 \\ doi:10.5539/ass.v10n23p78 URL: http://dx.doi.org/10.5539/ass.v10n23p78
}

\begin{abstract}
The global practice shows the need for concentration on the priorities and the definition of the pilot initiatives which measure up the country development strategy problems which have the elasticity in management and allow realizing the actions which support the end of purposes.

The innovative system of our country is at an uncertainty stage as it has to adapt to the newest tendencies of the open economy. In this regard the existing models of functioning change with the updated are obvious. The polarization or focusing of public authorities, the industrial, scientific, research enterprises and business communities' actions on these changes is especially necessary. In the developed countries the correctly designed information component of all infrastructures is the effective innovative activity basis. Deficient information about the new development and innovations of concerned parties is the main recurring problem of an existing information component in the Russian conditions.

The author's approach to the problem solution assumes the development and amplitudinous use of existing and showing positive dynamics infrastructure objects; the study of missing links; the development of methodical, standard, legislative tools which promote the effective functioning of the infrastructure objects. It will allow creating the system which will promote the advance of new knowledge and technologies to the market outlets. The actions provide the creation of the uniform information platform of "the Innovations of Russia" which will be capable to accumulate information for the purpose of the real and concrete support of business and scientific community.
\end{abstract}

Keywords: business community, governmental sector, research organizations, uniform information platform

\section{Introduction}

Nowadays a huge number of the organizations which are independent from each other and are focused on the transfer and the commercialization of technologies function in the territory of the Russian Federation. The deficiency of a uniform information platform about their activity doesn't give the chance to increase the efficiency of their work, doesn't allow to give in a complex and systemically the state support for the purpose of the innovations sphere development. The formation of a uniform information platform will promote the innovative development, the formation of opportunities for the experience interregional exchange, to develop the workforce capacity (Sibirskaya, Stroeva, Gubareva, \& Mikheykina, 2014).

At the round-table meeting at the III Moscow venture forum which covered the problems of innovative infrastructure development Yanul Natalya declared that there is not uniform federal agency of coordination of innovations production in our country. "The Ministry of Education and Science of the Russian Federation is the knowledge generation and financing of the science and educations directions. the Ministry for Economic Development is the innovative infrastructure, the construction of business incubators, technology parks. The department doesn't solved the questions about how the innovative projects will be there. The Ministry for Industry and Trade is the independent decisions about the modernization of the native industry, and the state 
corporations have own programs, that is coordination is absent", - Yanul Natalya (2009) commented her point of view.

In spite of the fact that quite a few time passed away from the moment of the round-table meeting, the situation didn't change. Authors agree with experts of the round table and suggest creating a uniform information platform of "the Innovations of Russia".

The high-quality information exchange will be the main link of the organizations activity success. All information has to pass the interpretation by the recipient who has to react, having provided to the sender the response information. It is possible to speak about the efficiency if the information exchange is capable to provide the expected results achievement. For which reason there is a need to transform the existing system of the information exchange in order to not leave all arising questions and problems without the due cognisance (Sibirskaya, Stroeva, Khokhlova, \& Oveshnikova, 2014).

We consider that in work of a uniform information platform of "the Innovations of Russia" it is necessary to attract: governmental bloc; business bloc; research bloc; "civil society" bloc; "the organizations for advance technologies" bloc; "foreign partners" bloc that is all those who is involved in the solution of the country innovative development questions. As a result, the formation of the uniform information platform of "the Innovations of Russia" tools will promote the effective use of the state, enterprise and scientific potentials (Shade, 1998; Massey \& Quihtas, 1992).

The substantiation of the uniform information platform of "the Innovations of Russia" creation is based on the Strategy of innovative development of the Russian Federation till 2020. In strategy, it is said that the elaboration of the innovative development opportunities general vision of the concrete branches and the direction by the science, the state, business structures, consumers, and also the formation and implementation of the development and researches perspective programs by dint of the certain mechanism of technological platforms becomes the coordination important element (the Strategy of innovative development of the Russian Federation for the period till 2020, 2011).

The director of the Kurchatov institute Mikhail Kovalchuk told on the site which devoted to nanotechnologies in Russia that "the three links - the state, business and science have to work together for the innovative economy success and the leader in this trio has to be the state" (Kovalchuk, 2008).

The center of regional problems learning provided the information about ten innovative events of 2012 among them the Forum of "Open innovations". The authorities, business and the science took part in the Forum. Their activity is aimed at the innovative economy development of our country. All pollees confirm about the need for coordination of actions. It confirms the topicality and need of a uniform information platform of "the Innovations of Russia" (The center of regional problems learning, 2012).

\section{Describing the Domain}

In author's representation the uniform information platform of "the Innovations of Russia" is the organizational framework which accumulates systemically the information infrastructure of governmental, business, research blocs, "civil society" bloc, "intermediary organizations" bloc, «the organizations for advance technologies" bloc and "foreign partners" bloc.

The created uniform information platform of "the Innovations of Russia" will be: to collect and accumulate the database, to train and render the information support, expert support of all interested parties (the science, the production, the business, the state, etc.); to form the databases of innovations by the allocation of enquiries and offers.

\section{Methods and Materials}

The formation of any organization is surely connected with the demonstrating strategy. In our case the strategy is the concrete representation about what the uniform information platform of "the Innovation of Russia" is, what its purposes, tasks, internal and external resources, opportunities and risks are.

The strategy of the uniform information platform formation has to be constructed on the basis of learning of the following parameters:

1. The mission of a uniform information platform "Innovations of Russia" (for whom it functions; what problems it solves and how).

2. The information, financial, material, human support and security (the internal context). 
3. The economic and political environment, the legal conditions, the general tendencies and public priorities (the external context).

The strategy of a uniform information platform of "Innovations of Russia" is based on the concurrence of priorities, internal opportunities and external conditions.

After definition of the uniform information platform of "Innovations of Russia" strategy, it is necessary to detail a number of very important questions:

first, who and in whose interests the uniform information platform work has to be organized;

secondly, what activities;

thirdly, what kinds of activity will the platform carry out;

fourthly, what organizational and legal form will it have;

fifthly, who will be the services user of the uniform information platform.

Authors developed the functioning algorithm of the uniform information platform which is shown in figure 1 .

The functioning algorithm of the uniform information platform of "the Innovations of Russia" (figure 1) shows that the information is accumulated in a database on the basis of such blocs as: governmental, business, research; "civil society"; "the organizations for advance technologies" ; "intermediary organizations"; "foreign partners". As a result of created and constantly updated database the uniform information platform will provide the information services in questions of innovative activity in the following directions: the commercialization, patenting, the consultancy, legal services, the organizational development, educational and consulting services (Stoneman, 1995).

On the basis of the conducted researches, authors separated the structural elements which information is significant and important for development of innovations:

1. "Civil society" bloc. Unfortunately, now the limited number of the civil society organizations takes part in innovative development or its support in Russia. At present we can tell only about two large organizations: The all-Russian public organization of small and average business of Russia and the Russian Union of Industrialists and Entrepreneurs which directly participate in various discussions and also in formation of optimum decisions on development of national innovative system. Also the Chamber of Commerce and Industry of the Russian Federation takes measures in this sphere.

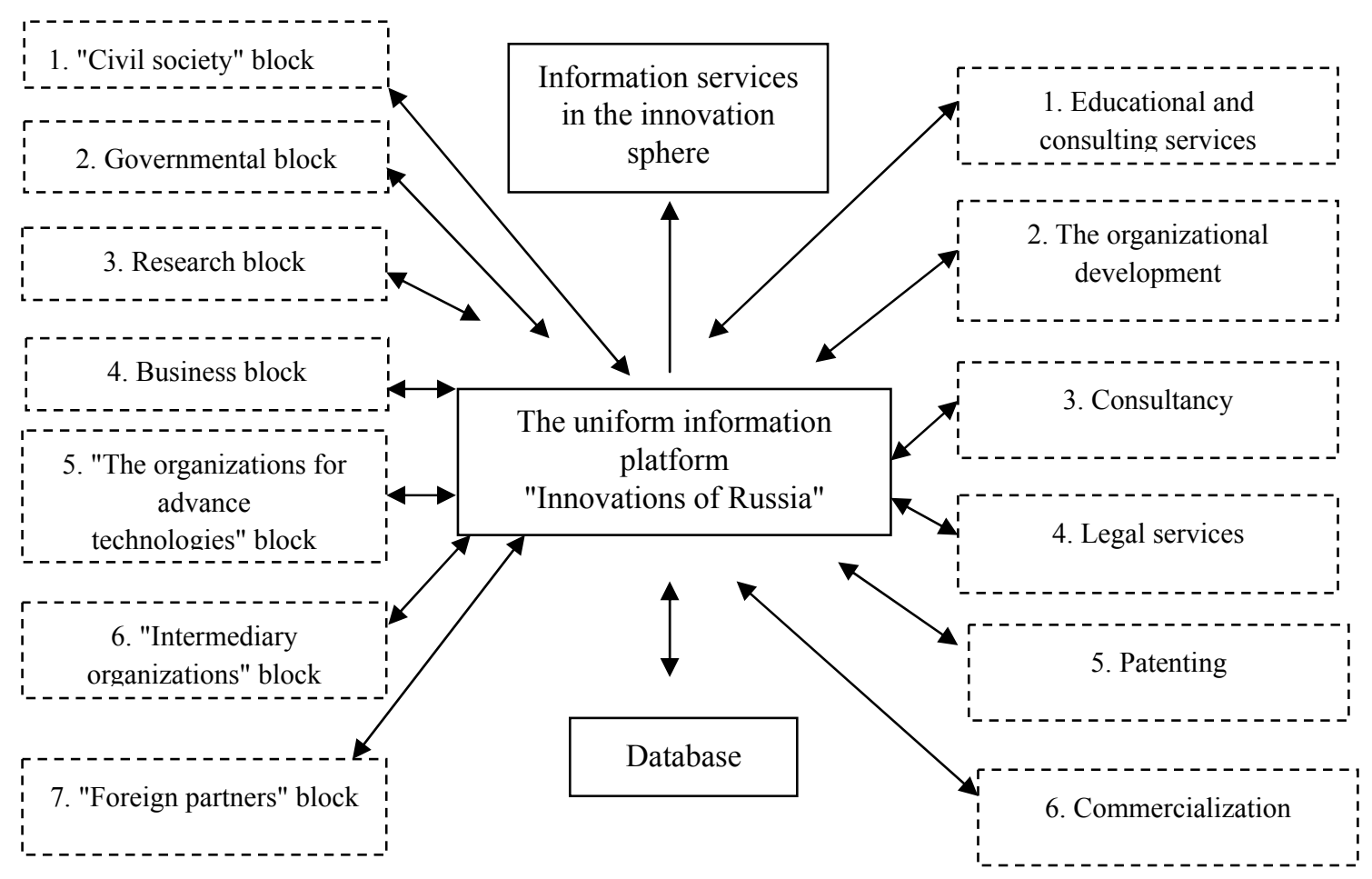

Figure 1. The uniform information platform of "Innovations of Russia" 
2. The governmental bloc is characterized by the formulation, financing and stimulation of innovations. It represents the formed system of various funds, agencies and the ministries. The weak link of the Russian system is the deficiency of uniform representation and policy vision in the field of innovations which accepted by all key participants. There is not document, the program or the macro level project in which all objects and subjects of innovative activity would be interested. We confirm that actually there are not the uniform direction and value of national innovative policy in the country. It is possible to confirm that there are the low interest of the branch ministries in documents formation of innovative activity development and the deficiency of system coordination according to various programs and projects and frequent restructuring of authorities. Besides, with very frequent frequency, there are problem situations of innovative policy practical realization, the deficiency of information access and inopportuneness of information distribution, not carrying out monitoring and not drawing up databases. The information component about the activity of all departments and the subordinated structures which define the policy, carry out the coordination, financing and regulation in the scientific and technical sphere of Russia is offered in this bloc (Boudeville, 1966; Common, 1931).

3. Research bloc. This block will allow accumulating the necessary information about the activity of such establishments as: the institutes, universities, private institutes, academies, Russian Academy of Sciences; branch research organizations; branch academies of Sciences, etc. Also there it is possible to provide information on all registered and functioning and nonfunctioning small innovative enterprises which are created on the basis of higher educational institutions and business incubators.

4. Business bloc. On the way toward the innovative economy the business sector plays an advance guard role with the effective social policy which is based on liberal values. The business sector plays a role of the locomotive which is capable to remove present economy into steady developing condition. The modern economy isn't able to keep the integrity and competitiveness without continuous development and effective functioning of business. The information component about all business activity in the territory of the Russian Federation and beyond its limits is offered in this bloc. The component allows to coordinate the actions which have the aim at the innovative development.

5. "The organizations for advance technologies" bloc. Such structures as: business incubators, centers for a technology transfer, science and technology parks, etc. belong to the organizations for technologies advance as to a link between the state and private organizations. The organizations for technologies advance have essential advantages to ambitious businessmen training, to development of the small innovative enterprises by granting to them a complex of services and the resources which are necessary for effective development of the new companies and firms for the purpose of their conclusion to higher level of global development, incorporating or sale, for the purpose of further development. These organizations cultivate new businessmen and help to grow them to the brand company. During this period of development, the majority of beginning projects and the companies are most attackable.

6. "Intermediary organizations" bloc. Nowadays such subject of the market as the marketer of scientific and technical products is very essential and needed. He is the intermediary between the market and the author who possesses unique opportunities and abilities. The author of scientific and technical products trusts the intermediary who has to be able to work at the market that is to know all specifics and features of branch requirements; also to have abilities to control the developer for the purpose of the subsequent acceptance of the executed works.

7. "Foreign partners" bloc. In this bloc we will separate such forms of participation as: 1) branches and offices of the international corporations that is the structural organization of corporation which is carrying out the direct investments; 2) alliances that is some organizations which are united for performance of any contractual obligations. In this case the existence of reliable and constant sources of financial means has the significant importance; 3) attracted state, own sources of financing (noncommercial); 4) the support of research and developmental works and commercialization.

With an eye toward the long-term character of policy in the innovations sphere the governmental bloc is obliged to support and finance the realization priority and pilot development. Governmental, business, research and other blocks have to be integrated the uniform concept of development. It will allow the innovative process participants to develop in the uniform constructive direction. All enumerated blocs which are entered the formation of a uniform information platform of "Innovations of Russia" are interconnected and interdependent, and also have to be supplemented and be corrected in process of occurring changes for the purpose of rendering the qualified and full list of services: 
1. Educational and consulting services. This type of service is extremely important for the solution of the increase of economic literacy problem of the scientific shots and businessmen. Undertaken various studies showed that investment project development is widely evolved in other words business planning is performed by the qualified experts but businessmen consider that the received results are formal in order to start conducting negotiations. Actually the deficiency of economic knowledge provokes the difficulty in reading and understanding of economic categories, performance expectations and the received results. And as a result the businessman has not absolutely adequate idea of the opportunities, not competently conducts negotiations on attraction of borrowed funds with the subsequent problems at their return. In regions there is a deficiency of the qualified patent agents out of the central regions. Training of such experts is extremely necessary. There is a need for maintenance of transactions by the qualified experts in sales to foreign buyers. In this connection the competent experts specially prepared and able to give an assessment to the business are necessary.

2. The organizational development. From the point of management view the concept of organizational development is so far a subject of thorough disagreements. The organizational development is connected with a huge complex of actions for transformation, retraining of activity and plurality of receptions, ways and methods which are applied to assistance to all types of the organizations for increase in efficiency of functioning. Organizational development is the management of changes in the organizations, as a rule, in consequence of the reasons such as amalgamation, integration, merger, subdivision, change of production technologies and scales, entering of updating in internal and external environment of the enterprise, changes in the management personnel structure. Some types of development are inherent in organizational development: evolutionary, planned, spontaneous, structured, unstructured, directive, joint, personal, extra personal, revolutionary.

3. Consultancy. When rendering consulting services it is supposed: the help in a choice of the qualified businessmen and perspective projects; the assistance to new business projects; the organizational support through operative and strategic business planning; consultations on development of innovative activity; training of the effective management; marketing consultation; professional business consultation; the realization of monitoring and assessment of business projects; the help in finding of offices at "business incubators". The consultancy helps: to find weaknesses of the enterprise activity and to change a development vector in due time; to solve more global problems and to reach the new levels of development by means of business plans introduction of commercial and investment projects and formation of the current financial and economic account system.

4. Legal services. In the conditions of the Russian legislation frequent variability the continuous control and adequate response to the changes give the chance to save means and to build further strategy of development correctly. Rendering services in the law sphere is constantly saleable activity. Legal services are the detailed consultation and the help in different kinds of questions, for example, gathering documentation, the analysis of business prospects in a court, the realization of the checks and other (Martov, 2013).

5. Patenting. Nowadays there is a huge number of patenting documentation and its quantity constantly increases. The Russian researchers which create the intellectual property new object with the subsequent entry into the market have to understand all variety of this information. At filing of an application for acquisition of patent it is necessary to take the long term of pendency of application, and also the fact that the protection by the patent extends only on the country where it is received - and that filing of an application abroad can be made only after filing of an application for the territories of the country of organization registration (Zaramenskikh, 2014). Other aspect is the fact that many technologies take to reverse-engineering. In other words, having bought a product and "having sorted" it is possible to understand, reproduce, change or simply to copy the principle. In spite of the fact that similar actions can contradict the law of copyright and the legislation in the field of patenting, as a whole it is impossible to be protected from them. For this reason often the organizations prefer to keep the technologies which aren't giving in to reverse-engineering, in the "know-how" status, without submitting the patent applications which are obliged to them to open the detailed information. On the other hand, such actions represent the risk of that the other team will put on the market and will patent a similar innovation by own efforts.

6. Commercialization. In the conditions of post-industrial society formation the development of technologies is the new factor of effective formation of the innovative type economy. It isn't enough the existence of technologies for successful formation of the new type economy. The effective system of technologies transfer and commercialization is necessary. In modern global economy in the conditions of an aggravation of competitive processes the development of technologies commercialization mechanisms is a backbone factor of innovative development and provides the noticeable increase of the countries' welfare (Zaramenskikh, 2014). The process of technologies commercialization begins at the same time with the moment of its creation. The 
efficiency of commercialization process depends on the possession of timely necessary information and on the qualified consultation.

\section{Results}

So, we offered to create a uniform information platform "Innovations of "Russia" which will simplify, learn, show and render various assistance in innovative activity development of all subjects and objects which function not only in the territory of the Russian Federation but also beyond its limits. We described the strategy, the mission, internal and external environment of the uniform information platform, and also constructed the algorithm of its functioning with the detailed description of all interconnected and interacting blocs.

We consider that after the start of this information platform, the results look forward to it won't be long. And it will be possible to estimate the effect from activity of a uniform information platform "Innovations of "Russia" on a number of quality and quantitative indicators such as: the increase of the commercial offers quantity; the increase in number of the signed commercial contracts; the users growth by services of a uniform information platform will be fixed every day; the increase of the investors and clients number; the increase of the productivity; the growth of the signed contracts number; the increase of the research works, with financial support both Russian and the foreign organizations and the companies; the realization of joint researches; the really functioning small innovative enterprises and their continuous growth; the increase of investments at the initial stages of scientific researches; the increase of the attracted investments; the positive dynamics from the development of competences in researchers and businessmen on the questions about the technologies commercialization; the growth of the submitted patent applications, licenses, "know-hows" and various programs.

\section{Conclusion}

The uniform information platform of "Innovations of Russia" affects the interests and solves the problems of a great number of managing subjects, and author's offers are based on the development of such information space where the database about all organizations which are entered in the information infrastructure will be formed.

We consider that at realization of a uniform information platform, the information of learning and distribution of innovative activity positive experience is provided to users of its services. The formation of a uniform information platform will allow: first, to structure the information search systems and databases on advanced technologies and development in the innovations sphere; secondly, to find and accept the correct technical and administrative decisions; thirdly, to define the partners for the realization and/or financing of business projects; fourthly, to systematize the information stream for the effective activity of the interested organizations.

\section{References}

Boudeville, J. R. (1966). Problems of Regional Economic Planning (p. 11). Edinburgh.

Center of regional problems learning. (2012). 10 main innovative events of 2012. Retrieved April 4, 2014, from http://www.rusnanonet.ru/news/82924/

Common, J. (1931). Institutional Economics. The American Economic Review, 21(4), 648-657

Cooper, R. G. (1985). Selecting Winning New Product Projects: Using the NewProd System. Product Innovation Management, 2, 34-44. http://dx.doi.org/10.1016/0737-6782(85)90014-1

Kovalchuk, M. (2008). For success of innovative economy the state, business and science have to work synchronously. Retrieved March 3, 2014, from http://www.nanonewsnet.ru/blog/nikst/dlya-uspekhainnovatsionnoi-ekonomiki-gosudarstvo-biznes-nauka-dolzhny-deistvovat-sinkhro

Lundvall, B. A. (1992). National Systems of Innovation. Towards a Theory of Innovation and Interactive Learning (pp. 23-44). London: Pinter Publishers.

Martov, S. N. (2013). Information infrastructure of the small innovative enterprises: A monograph (p. 184). Oryol: JSC Nauchnoye obozreniye.

Massey, D., \& Quihtas P. (1992). Wield. High Tech Fantasies, Science Parks in Society, Science and Space (p. 55). Routledge.

Nauwelaers, C., \& Alasdair, R. (1995). Innovative Regions. A comparative Review of Methods of Evaluating Regional Innovation Potential (p. 160). Project SPRINT-EIMS, 94/98.

Shade, L. R. (1998). A gendered perspective on access to the information infrastructure. The Information Society, 14, 33-34. New York. http://dx.doi.org/10.1080/019722498128999 
Sibirskaya, E. V., Stroeva, O. A., Gubareva, L. I., \& Mikheykina, L. A. (2014). The monitoring of the subject and object of the economic activity population in the innovative sector. Life Sci J., 11(8s), 292-296

Sibirskaya, E. V., Stroeva, O. A., Khokhlova, O. A., \& Oveshnikova, L. V. (2014). An analysis of investment-innovation activity in Russia. Life Sci J., 11(7s), 155-158

Stoneman, P. (1995). Handbookof the Economics of Innovation and Technical Change (p. 25). London: Blackwell.

Strategy of innovative development of the Russian Federation for the period till 2020 (it is approved as the order of the Government of the Russian Federation, the 8 of December, 2011 No. 2227-r. Retrieved February 13, 2014, from http://www.garant.ru/products/ipo/prime/doc/70006124/\#ixzz39VTZsbes

Stroeva, O. A., Sibirskaya, E. V., Khokhlova, O. A., \& Oveshnikova, L. V. (2014). Regionalization of the innovation management process. Life Sci J., 11(8s), 297-301

Yanus, N. (2009). The innovations coordination. Retrieved February 23, 2014, from http://www.strf.ru/ innovation.aspx? CatalogId $=223 \& d \_$no $=21056$

Zaramenskikh, E. P. (2014). The commercialization of technologies: A monograph (p. 125). Novosibirsk: TsRNS publishing house.

\section{Copyrights}

Copyright for this article is retained by the author(s), with first publication rights granted to the journal.

This is an open-access article distributed under the terms and conditions of the Creative Commons Attribution license (http://creativecommons.org/licenses/by/3.0/). 